\title{
CORRIGENDUM
}

\section{Conflict, Peace, and the Evolution of Women's Empowerment - Corrigendum}

Kaitlyn Webster, Chong Chen and Kyle Beardsley

DOI: https://doi.org/10.1017/S0020818319000055; Published online by Cambridge University Press: 26 March 2019

In the original publication of Webster, Chen, and Beardsley (2019), an error occurred in Figure 6b. The correct Figure $6 \mathrm{~b}$ is reproduced below:

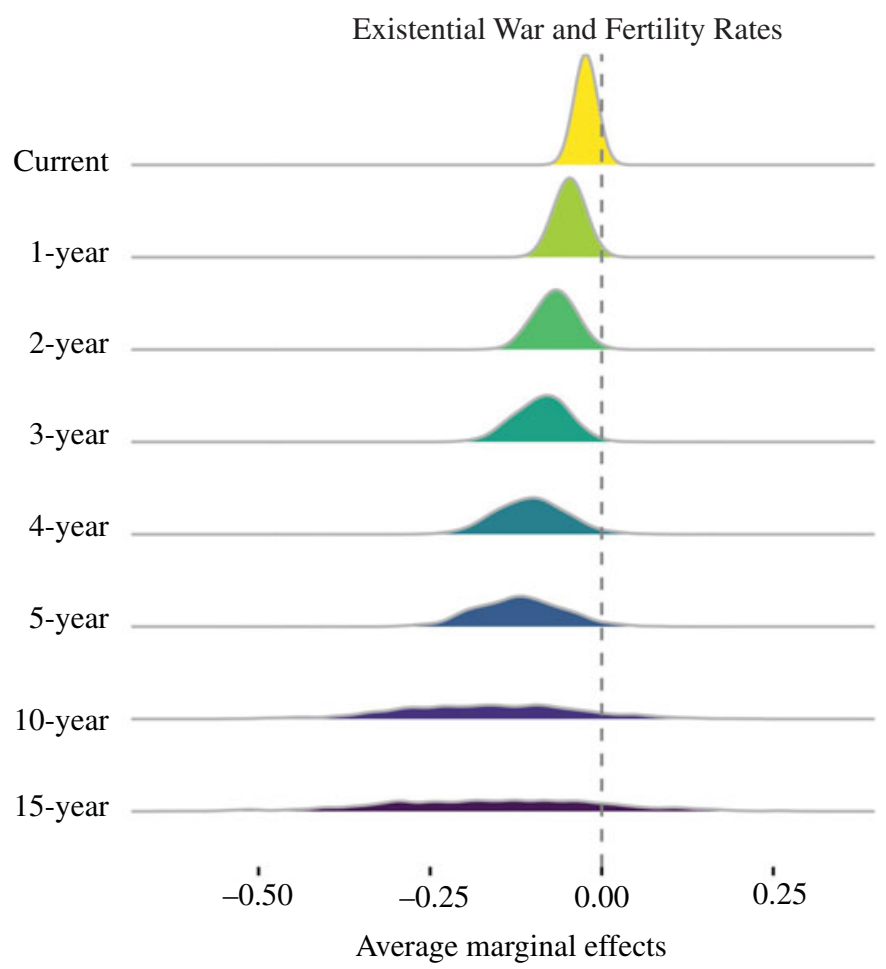




\section{Reference}

Webster, Kaitlyn, Chong Chen, and Kyle Beardsley. 2019. Conflict, Peace, and the Evolution of Women's Empowerment. International Organization 73 (2):255-89. 